\title{
Research Paper \\ The Relationship between Socioeconomic Status and Cyberspace Addiction and Sport Tendency in Primary School Students
}

\author{
Gholamreza Zolfaghari ${ }^{1}$, Fahimeh Adib Saber ${ }^{* 2}$ \\ 1. M.A. Student in Sport Management, Rasht Branch, Islamic Azad University, Rasht, Iran \\ 2. Assistant Professor, Department of Physical Education, Rasht Branch, Islamic Azad University, Rasht, Iran
}

Citation: Zolfaghari G, Adib Saber F. The relationship between socioeconomic status and cyberspace addiction and sport tendency in primary school students. J Child Ment Health. 2021; 7(4): 284-296.

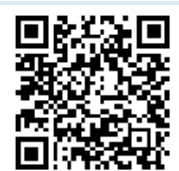

URL: http://childmentalhealth.ir/article-1-1062-en.html

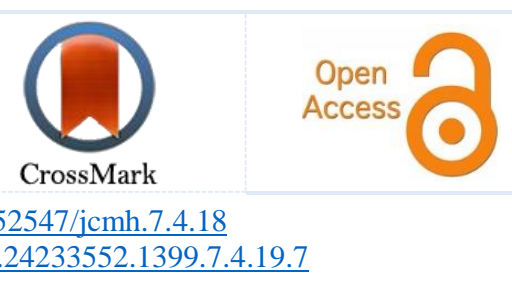

\section{A R T I C L E I N F O}

Keywords:

nternet addiction, exercise tendency, socioeconomic status, primary school students

Received: 31 Aug 2020

Accepted: 11 Dec 2020

Available: 17 Mar 2021

\section{A B S T R A C T}

Background and Purpose: Several studies indicate that the socioeconomic status of parents and the prevalence of Internet and cyberspace use have reduced children's tendency to mobility and physical activity; accordingly, the present study was conducted to investigate the relationship between Internet use and socioeconomic status of parents and the exercise tendency of primary school students.

Method: The present study was descriptive-correlational study. 230 students were selected by cluster sampling from among the fourth to sixth grade students of Rasht city in the academic year 20192020. Internet Addiction Test (Kimberly Young, 1998), Socio-Economic Status Questionnaire (Ghodratnam, 2013), and Exercise Tendency Questionnaire (Naji, 2010) were used to collect the data. Pearson correlation coefficient and multiple regression analysis were used to analyze the data. Results: Results of multiple regression analysis showed that the income and education level of parents predicted 0.013 and 0.027 of the variance of the children's exercise tendency, respectively ( $p$ $<0.05$ ). The results of this study also showed that there is no significant relationship between the exercise tendency and addiction to cyberspace.

Conclusion: Based on the findings, it can be concluded that the socioeconomic status of parents can have direct and indirect impact on the exercise tendency level and physical activity of children.

* Corresponding author: Fahimeh Adib Saber, Assistant Professor, Department of Physical Education, Rasht Branch, Islamic Azad University, Rasht, Iran.

E-mail: Adibsaber@iaurasht.ac.ir

Tel: (+98) 1333424073

2476-5740/ (C) 2021 The Authors. This is an open access article under the CC BY-NC-ND license

(https://creativecommons.org/licenses/by-nc-nd/4.0/). 


\section{Extended Abstract}

\section{Introduction}

Over the past decades, the industrialization of societies has affected all traits of adults, children and adolescents, including their mobility (1). Environmental conditions and their effects on various aspects of child development are very important and vital (2). Since students form a large group of society and have a significant impact on the future of the main cycles of the country, paying attention to their general health is very important and necessary (3). Nowadays, sport is an important tool in the hands of governments to guide people towards goal setting, because the main means of public education in contemporary society is the sport industry (4). Despite all the benefits mentioned for sports, today the country is facing the growing disinterest of students in sports. Among the factors that reduce the students' tendency to exercise, we can mention the socioeconomic status of families and its indicators such as education level, economic status and number of family members (3).

Some researchers believe that people with higher socioeconomic status enjoy higher health and can improve their health status by more participation in physical activities (6-10), while parents with lower income and education level have children with lower activity levels (10-13). Others argue that social factors do not have a significant effect on the sport participation of the family, while economic factors significantly influence it (3). The results of other studies showed that there is no significant relationship between socioeconomic status and the level of physical activity of high school and middle school students (14).

Another factor that influences the exercise tendency of students is virtual network addiction. The gap between family members and the deprivation of healthy and constructive communication, isolationism, extreme individualism and many emerging harms are the dangers that arise due to the unrestrained presence of users in cyberspace and social networks (16). The prevalence of this phenomenon can endanger their psychological health (17). In Iran, according to statistics, adolescents and young people constitute a large amount of those at the risk of internet addiction
(18) and the number of internet users in this country ranked first in the Middle East (19). Excessive use of Internet not only may take a lot of time and make the user lonely and isolated (20) but also may have a devastating effect on health, social life, academic performance, and memory (21). Young people who spend more time on social and family activities experience lower rates of cyberspace and Internet addiction $(22,23)$. Also, the results of a study conducted on the effect of Internet use on physical activity, sport and academic performance of students aged 14-16 showed that there is a relationship between Internet use and health (including the presence of abnormal reactions and negative emotions) and school performance of adolescent students (24). Another study found that learners with higher cyberspace addiction had lower academic performance (25).

Therefore, whereas mental health of adolescents and young people is one of the most important topics in the field of psychology and sociology and nowadays many adolescents in the lower grades have access to mobile phones and Internet and use them in various ways and by considering this fact that most of the research conducted in Iran on cyberspace addiction have focused on epidemiology of this issue and less attention has been paid to the study of the relationship between sport and cyberspace addiction, the present study was conducted to determine the relationship between exercise tendency and internet addiction of primary school students and their parents' socioeconomic status; aiming to promote sport in schools on one side and to improve the students' physical and mental health on the other side.

\section{Method}

The present study was a descriptive-correlational research. The population included all the primary school students in the public schools of District 2 in Rasht (Iran) during the academic year 2019-2020. Among them, a sample of 320 students (178 boys and 142 girls) was selected by cluster sampling. After taking the necessary permissions from Rasht Azad University, and obtaining the list of public primary schools in District 2 of Rasht from the Education Organization, 10 schools (5 girls 'schools 
and 5 boys' schools) were randomly selected. Then, in proportion to the number of students in each school, 320 students were selected according to the inclusion criteria (such as complete parental consent, studying at grades 4 to 6 of primary school, having non-addicted parents, and living with both parents) and exclusion criteria (such as dissatisfaction, lack of parental cooperation, and physical or psychological problems in the students). The Socioeconomic Status Questionnaire of Ghodramnama, Heydarinejad and Davoodi (26), the Exercise Tendency Questionnaire of Naji etal. (quoted by 27), and Internet Addiction Questionnaire of Kimberly Young (28) were completed by the parents. After giving the written consent, parents were provided with the questionnaires online. They were also assured that the information obtained would be used solely for research purposes and would be kept confidential and that there was no need to mention their name when answering the questionnaire. Other ethical considerations, such as being free to withdraw from the study, were also considered. SPSS 26 software was used to analyze the data.

\section{Results}

Table 1 reports the descriptive statistics and correlation matrix of research variables. There is a significant positive relationship between the education level of parents and the exercise tendency of students $(r=$ 0.116 ). Also, the relationship between the income level of parents and the exercise tendency of students is negative and significant at the level of $0.05(\mathrm{r}=$ $0.11)$.

Table 1: Descriptive statistics and correlation matrix of research variables

\begin{tabular}{ccccccccccc}
\hline No. & Variable & Mean & SD & $\mathbf{1}$ & $\mathbf{2}$ & $\mathbf{3}$ & $\mathbf{4}$ & $\mathbf{5}$ & $\mathbf{6}$ \\
\hline 1 & Exercise tendency & 78.14 & 5.89 & 1 & & & & & & \\
2 & Cyberspace addiction & 44.67 & 10.12 & 0.028 & 1 & & \\
3 & Income level & 2.38 & 0.919 & $*-0.11$ & $* 0.138$ & 1 & \\
4 & Social level & 2.44 & 0.90 & 0.090 & $* 0.111$ & $* 0.929$ & 1 & \\
5 & Level of education & 2.23 & 0.95 & $* 0.116$ & 0.015 & 0.060 & 0.009 & 1 & & \\
6 & Housing status & 2.65 & 1.48 & 0.629 & 0.010 & 0.038 & 0.014 & 0.030 & 1 \\
\hline
\end{tabular}

In explaining the exercise tendency of students in relation to the income and education level of their parents, it can be said that the sum of predictor variables $R^{2}=0.027$ explained and predicted the variance of the dependent variable, i.e. predictor variables explained $0.027 \%$ of the variance of children's exercise tendency in total. Also, the F value was significant for all research variables at the level of 0.05 , indicating that the variables had a significant effect on the exercise tendency of students. Besides, the effect of parental education level on children's exercise tendency $(\beta=0.123)$ was positive and significant at the level of 0.05 . The effect of parents' income on children's exercise tendency $(\beta=-0.118)$ was negative and significant at the level of 0.05 . The positive effect of parental education level on children's exercise tendency indicates that the higher the parental education level, the higher the children's tendency to exercise. But the negative effect of income level indicates that the higher the income of parents, the less their children tend to exercise.

\section{Conclusion}

In this study, the relationship between the socioeconomic status of parents and the rate of Internet addiction and exercise tendency in the primary school students in Rasht city was investigated. The analysis of the findings of the present study showed that there is a significant relationship between the exercise tendency in the primary school students and the socioeconomic status (i.e. the income and education level) of their parents. Findings of this study are consistent with the results of Sabra et al. (8) and Coles et al. (9). Sabra et al. showed that adolescents with high social and cultural status were more involved in sports activities (8). Also, Coles et al. found that children who came to school with facilities such as bicycles were more active in the sport activities of the school.

As far as the socioeconomic status is concerned, it has been reported that there is a two-way causal relationship between the inadequacy of the socioeconomic status and health; so that having a low socioeconomic status leads to poor health. Poor 
health, in turn, contributes to the stabilization of poverty (10). One possible reason for this may be that children from higher-income families face fewer financial barriers to engage in organized physical activities. In addition, less educated parents may have irregular working hours; therefore, they have less time for their children's entertainment. In contrast, in a review study, Stalsberg and Pederson approved the hypothesis that there is a relationship between socioeconomic status and physical activity, and that students with higher socioeconomic status are more active than children with lower socioeconomic status (13).

The results of this study also showed that there is no significant relationship between the tendency to exercise and addiction to cyberspace. The results of the present study were inconsistent with the findings of Koçak (23) and George and Elisavet (24). In his study, Koçak found that there is a significant difference between regular exercise and Internet addiction. Also, the period of Internet use of people who were regularly active was reduced. A possible reason for this discrepancy could be the difference in the age group of the participants in the small study. In this regard, George and Elisavet Concluded that Internet use had a direct positive relationship with health, including the presence of abnormal reactions and negative emotions and a direct negative relationship with the school performance of adolescent students.

Research shows that Internet addiction can have negative psychological, physical and physiological effects. Loneliness is one of the reasons for cyber addiction. In addition, people who spend more time on the Internet suffer from problems such as lower back pain, cardiovascular diseases and obesity, and there is a linear relationship between long-term use of cyberspace and obesity and sedentary lifestyle. Today, the importance of active living for personal and social health has become more tangible (23).

Although the present study faced limitations such as research population limited to primary school students and lack of attention to being an athlete or nonathletic as a mediating variable, but in general, based on the findings, it could be claimed that children of parents with higher level of income and education tend to exercise more and are more physical active. Since low level of physical activity is the most important risk factor for public health, the most effective method required is to improve the public health and encourage the community to perform regular physical activity. Therefore, it is suggested that the implementation of sports and physical activity be institutionalized from an early age, hours of physical education increase in schools, and more attention be paid to the enrichment of sports programs and physical education classes in schools to improve the health status as much as possible.

\section{Ethical Considerations}

Compliance with ethical guidelines: This article is taken from the master's thesis of the first author in the field of sports management, which was approved under the code 1172925943177481398160610 in Rasht branch of Islamic Azad University on February 17, 2017 and was defended on October 30, 2020. Also, the consent of the participants was gained and the principles of privacy and confidentiality were observed.

Funding: This study was conducted in the form of a master's thesis, with no sponsor.

Authors' contribution: The first author was the senior author and the second one was the supervisor.

Conflict of interest: There is no conflict of interest in this study.

Acknowledgments: We would like to thank all the parents and students who helped us implement this dissertation. 


\section{رابطه وضعيت اجتماعى -اقتصادى و اعتياد به اينترنت با تمايل به ورزش دانش آموزان مقطع ابتدايى

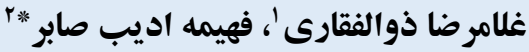

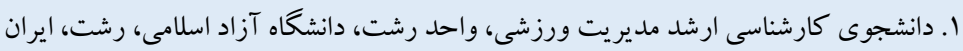

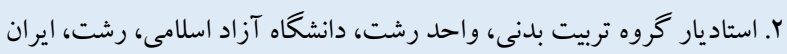

\section{جكيده}

زمينه و هدف: نتايج مطالعات متعدد حاكى از آن است كه وضعيت اجتماعى و اقتصادى والدين و شيوع استفاده از اينترنت و فضاى مجازى

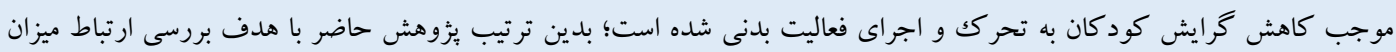

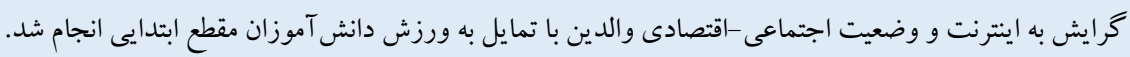

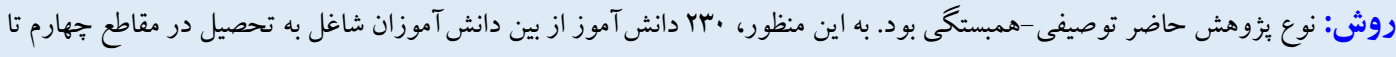

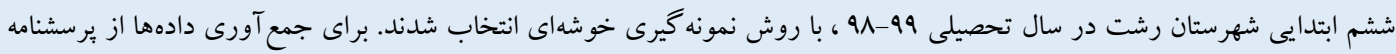

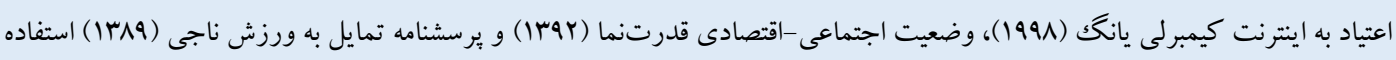

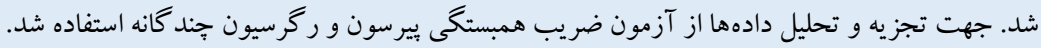

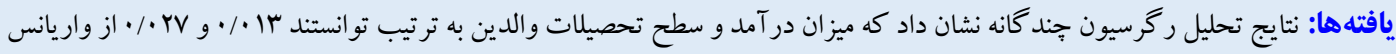

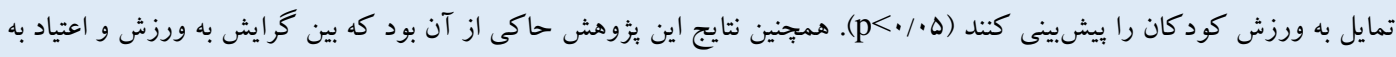
فضاى مجازى رابطه معنادارى وجود ندارد. نتيجه كيرى: طبق يافته هاى بهدست آمده مىتوان نتيجه گرفت كه وضعيت اجتماعى-اقتصادى والدين مى تواند بهطور مستقيم و غيرمستقيم بر ميزان تمايل كود كان به اجراى ورزش و وفائهايت بهدسائ بدنى تأثير داشته باشد.
مشخصات مقاله

كليدوازهها:

اعتياد به اينترنت،

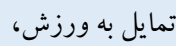

وضعيت اجتماعى-اقتصادى،

دانش آموزان ابتدايى

* نويسنده مسئول: فهيمه اديب صابر، استاديار كروه تربيت بدنى، واحد رشت، دانشكاه آزاد اسلامى، رشت، ايران.

رايانامه: Adibsaber@iaurasht.ac.ir

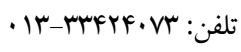


فعاليت بلدنى، مى تو انند وضسعيت سـلامتى خود را بهبود بخشند (9- +1) و والدين داراى وضـعيت در آمد و تحصـيلات بايين تر، داراى فرزندانى با

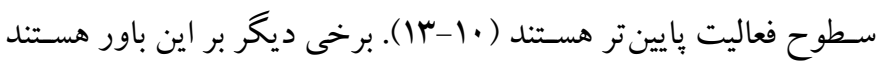
كه عوامل اجتماعى اثر معنادارى بر مشـاركت ورزشسى خانوار ندارد، ولى عوامل اقتصادى بر مشاركت ورزشى خانوار تأثير معنادارى دارد و به منظور افزايش ميزان مشـاركت ورزشـى خانوادهها، توجه به عوامل اقتصـادى مهم تر از عوامل اجتماعى اسـت (Y). ناهمسـو با اين يافته ها، نتـايج مطـالعـات ديكر حـاكى از آن بود كه بين وضــعيت اقتصــادىاجتماعى با ميز ان فعاليت بدنى دانش آموزان مقاطع دبيرستان و راهنمايى، رابطه معنادارى وجود ندارد (If) و بين وضسعيت اقتصادى-اجتماعى در سـه سـطح بالا، متوسـط و يايين، و ميز ان فعاليت بدنى جوانان و نوجوانان رابطه معنادارى وجود ندارد (ها). از عوامـل ديخر كـه بر كرايش دانش آموزان بـه ورزش تـأثير گـذار اسـت، مىتوان به اعتياد ' كود كك به شبكه هاى ' مجازى اشاره كرد. فارغ از تبعات و عوارض ناخوشـايند جسـمانى مانند كمتحركى، ضـعف و سـسـتى، وابستـكى و اعتياد به فضـاى مجازى با مشكلات روانى خاصى همراه است. شكاف ميان اعضاى خانواده و محروميت از ارتباط سالم و سـازنده، انزواطلبى و فردگرايى افراطى و بسيارى آسيبهاى نويديد از مخاطراتى اسـت كه در يى حضسور افسـار گسـيخته كاربران در فضـاى مجازى و شـبكههاى اجتماعى بروز بيدا مى كند (19). اعتياد به فضـاى مجازى به دليل دسـترسىى آسـان به سـر گرمىها، شـيوع بالايى در ميان

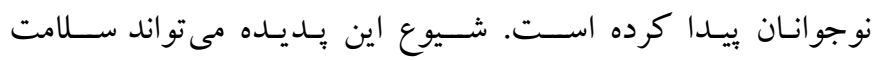
روانشناختى آنان را به خطر اندازد (IV). در ايران بر اسـاس آمار، گروه نوجوانان و جوانان بيشـتر از همه در معرض خطر ابتلا به اعتياد به فضاى مجازى قرار دارند (N) و حدود FA ميليون كاربر در كشــور وجود دارد كه درصــد زيادى از آنها را كود كان و نوجوانان تشـكيل مىدهند. اين تعداد كاربران اينترنتى رتبه نخست رادر خاورميانه به خود اختصاص دادهاند. آثار مثبت استفاده از اينترنت، به روز كردن اطلاعات، اسـتفاده از مطالب علمى، دسـترسى به فنـاورىهاى جديد و افزايش مهارت هاى اجتماعى اســت (19)؛ اما به موازات آن شـاهد كرايش نوجوانان به اتاقهاى كفتخً، عشـتهاى

2. Social networks
مقلهم

در طى دهههاى كذشــته، صــنعتى شــدن جوامع و ورود به فناورىهاى مختلف، تمامى ابعاد زندكى نه تنها در بزر كسـالان، كه در ميان كود كان و نوجوانان از جمله تحر كك آنها را تحت تأثير قرار داده است (1). شرايط محيطى و تأثير اتى كه بر جنبه هاى مختلف تحول كودكك دارد موضوعى بسـيار مهم و حياتى اسـت. منظور از محيط مناسب براى كود كان، فراهم كردن بســتر و عاملى مؤثر، جهت تحقق قابليت هاى بالقوه وجودى براى شناختن وجوه شخصيتى، جسمى و تأمين تحول كامل آنان است (Y). از آنجا كه دانش آموزان قشــر بزركى از جامعه را تشـكيل داده و تأثير زيادى ر آينده جرخههاى اصلى كشور مانند صنعت، اقتصاد، فرهنگك، و علم دارند، به همين منظور توجه به سـلامت عمومى آنها، موضـوعى بسيار مهم و ضرورى است (r). روى آوردن بـه فعـاليـت بـدنى بـه عنوان راهى براى كمـك بـهـ دانش آموزان به منظور كسـب مهارت، آمادگى، دانش و نخرش مثبت در راستاى رشد مطلوب، كسب سلامت عمومى، و به حداكثر رساندن فرصـتها براى اجراى فعاليتهاى بدنى استفاده مىشود. امروزه ورزش ابزارى مهم در دســت دولـتهـا براى هـدايست مردم به ســوى اهداف برنامهريزى شـده اسـت، زيرا عمده ترين وسـيله تربيت همكانى در جامعه معاصر، صنعت ورزش است (F). بـا وجود تمامى فوايدى كه براى ورزش ذكر مىشـود، امروزه كشـور شـاهد بىعلاقكى روزافزون دانش آموزان به موضسوع ورزش در مدارس است. از جمله عواملى كه باعث كاهش كر ايش دانش آموزان به ورزش مىشـود، مى توان به وضـعيت اجتماعى - اقتصـادى خانو ادهها و شـاخصهاى آن از جمله سـطح تحصيلات، وضعيت اقتصادى و تراكم خانواده اشـاره كرد (r). هر كس بر حسـب حرفه و برخى معيارهاى اقتصـادى و تحصسيلى، به يك طبقه اجتماعى و اقتصـادى خاص تعلق دارد. طبقات اجتماعى - اقتصـادى خانوادهها روى جنبههاى مختلف زندكى كود كان به خصوص كرايش كودك به سمت ورزش، انتخاب

رشته ورزشى، و ميزان فعاليت ورزشى تأثير فراوانى دارد (ه). برخى يزوهشـحران معتقدند افر ادى كه وضعيت اجتماعى - اقتصادى بالاترى دارند، وضـعيت سـلامتى بهترى داشـته و با افزايش شــركت در 
اسـت، بدين ترتيب مطاله حاضـر با تمركز بر اين موضسوع كه نتايج آن

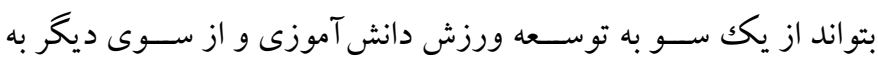

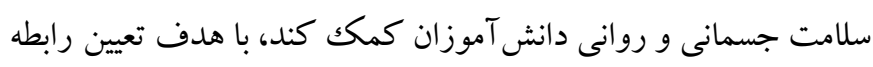

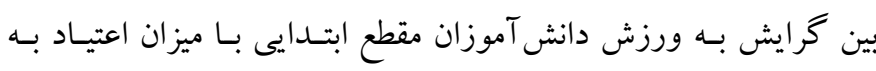
اينترنت و وضعيت اجتماعى - اقتصادى والدين شان انجام شد.

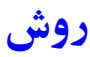
الف) طرح بزؤهش و شر كت كنند كان: روش يزوهش حاضر توصيفى از نوع همبسـتخى بود. جامعه آمارى بززوهش شـامل تمامى دانش آموزان

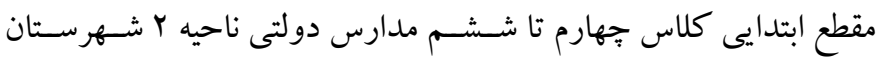

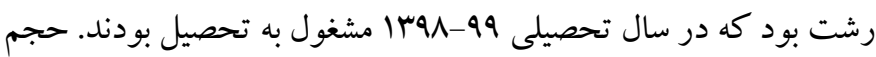

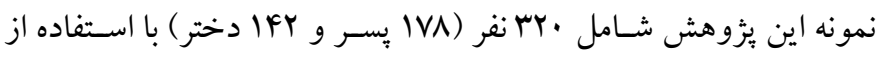
جدول كرسـى و مور گان بود كه به روش نمونه گيرى خوشــهاى بدين

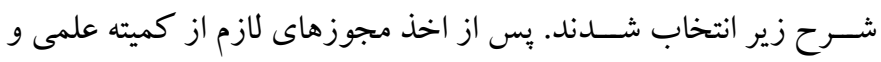

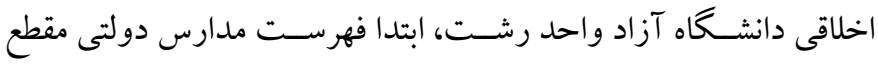
ابتدايى ناحيه Y شهرستان رشت از سازمان آموزش و يرورش كسب شد فرد

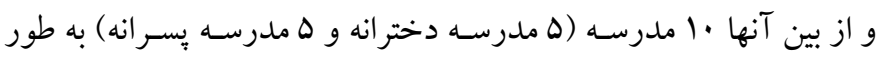
تصـادفى انتخاب، و سـيس متناسـب با تعداد دانش آموزان هر مدرسـه در

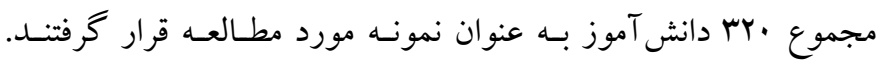

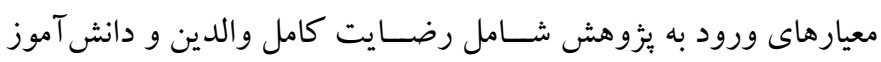

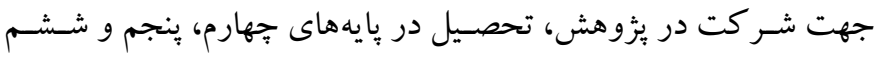

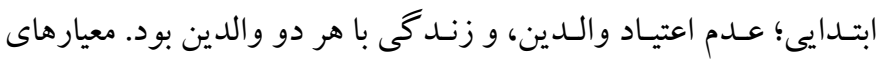

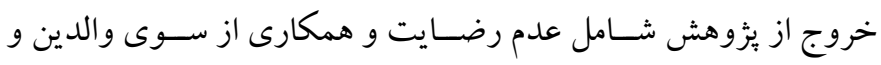
داشتن مشكلات جسمانى يا روانشناختى دانش آموزان در نظر گرفنه شدر.

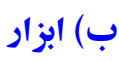

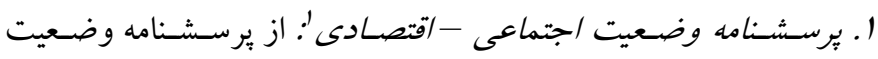

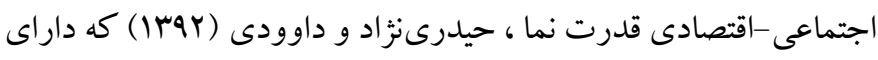

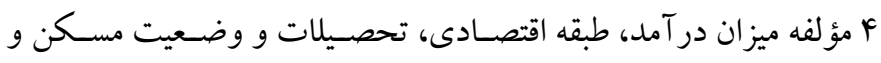

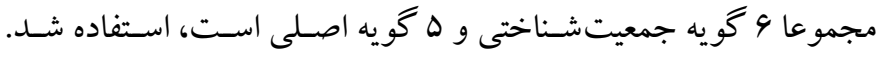

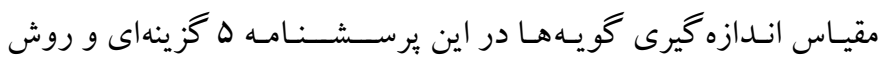

مجازى، كلاهبردارى، هرزهنگارى، سـرقت اطلاعات، و اخاذى هسـتيم

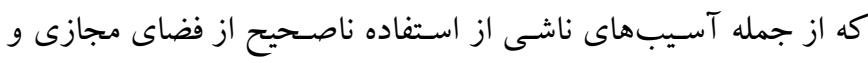

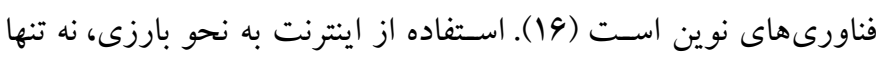

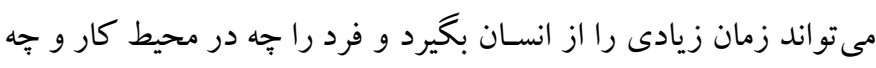

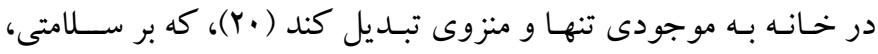

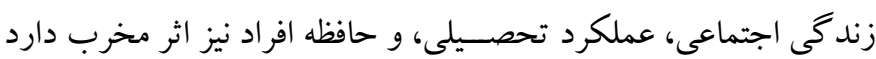

بررسىها نشـان داده است بين اعتياد به فضاى مجازى و اينترنت در

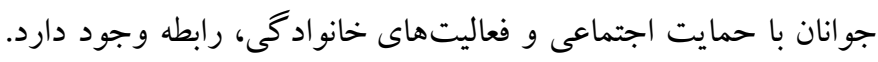

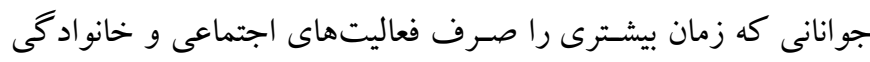

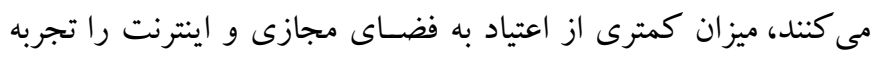

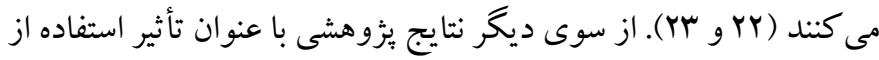

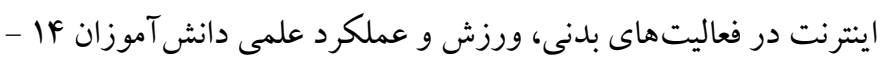

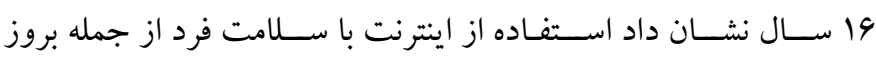
واكنش هاى غيرطبيعى، وجود احســاسـات منفى، و همجِين با عملكرد

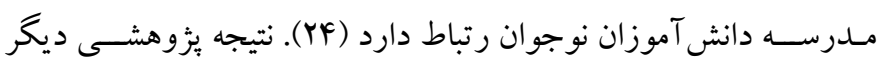

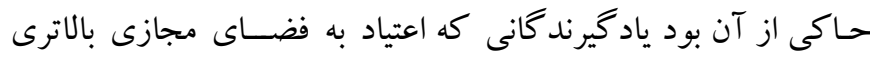
دارند از عملكرد تحصيلى بايين ترى برخوردار هستند (Yه).

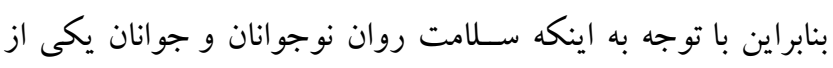

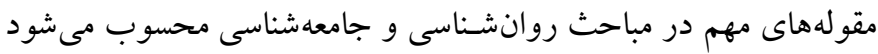
و با توجه به اين نكته كه امروزه بسيارى از نوجوانان در مقاطع پيايين

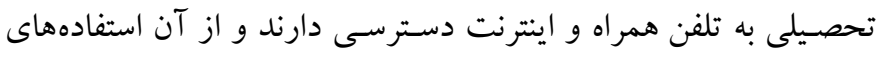

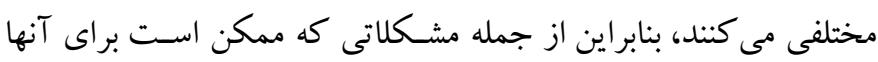
به عنوان آيندهسـازان جامعه در نتيجه اسـتفاده زياد با تلفن همراه و

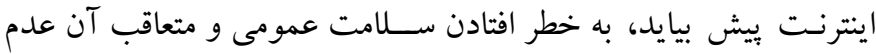

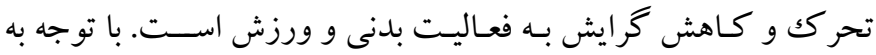

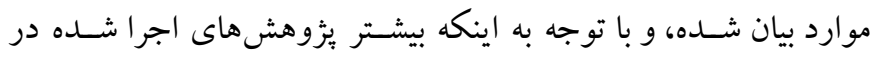

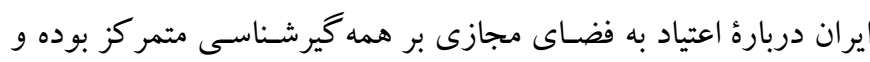

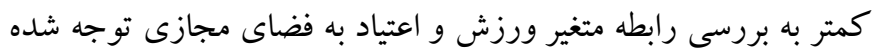

1. Socioeconomic Status 


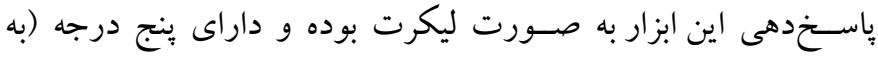

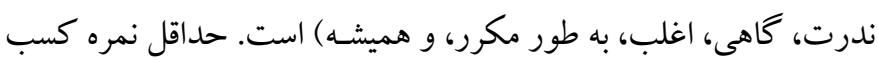

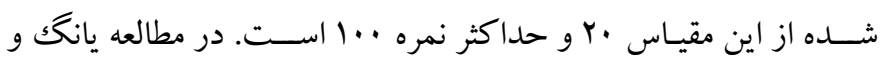

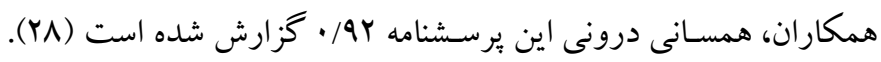

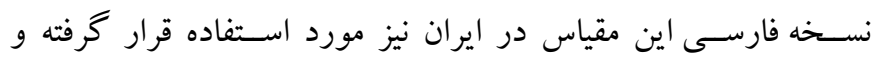

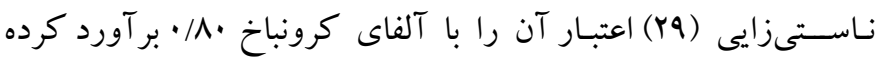

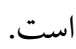

ج) روش اجرا: يس از اخـــ مجوزهاى للازم، افراد نمونه به شــــح ارائه

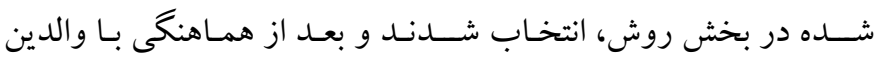

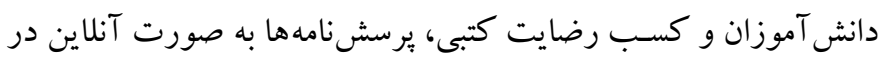
اختيار و الدين قرار گرفت. همجنين به آنها اطمينان داده شد كه اطلاعات به دسـت آمده فقط براى اهداف يزؤهشى اسـتفاده مى شـود و محرمانه

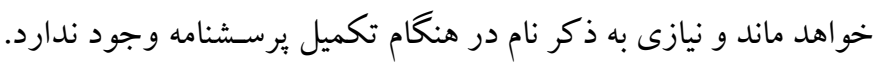

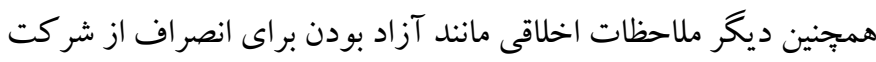

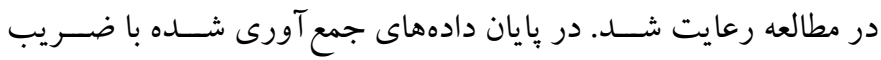

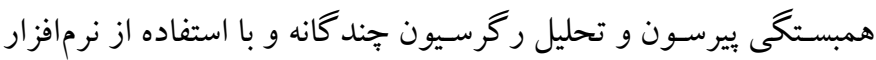
آمارى SPSS

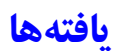

در جدول (ا، شاخص هاى توصيفى و ماتريس همبستكى متغيرهاى يزّوهش كزارش شده است. با توجه به جدول ا، ميزان تحصيلات والدين با ميزان تمايل به ورزش دانش آموزان رابطه مثبت معنادارى دارد (r=/ll9).

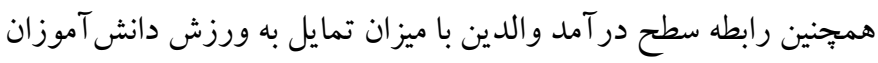

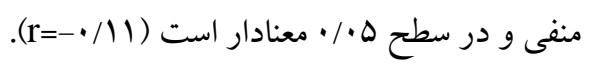

امتيـازدهى بـه ترتيـب خيلى بـايين (امتيـاز ا) تـا خيلى بالا (امتياز ه) بود.

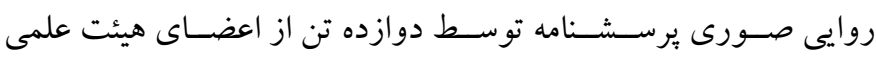
دانشكده تربيت بدنى دانشـاه شهيد جمران اهواز بررسى و وروس روايى سازه

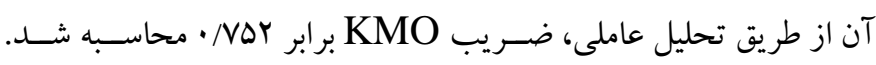

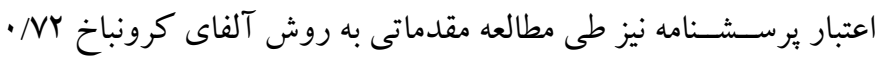
محاسبه شد (Y9). (19)

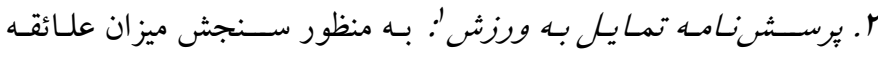

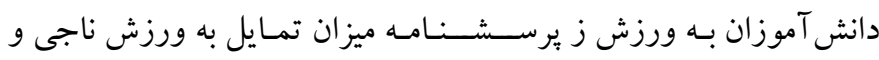

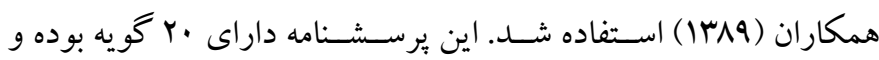
هـدف اصسلى آن، ســنجش ميزان تمـايـل بـه ورزش در افراد بـا ينج

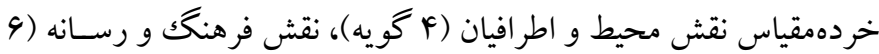

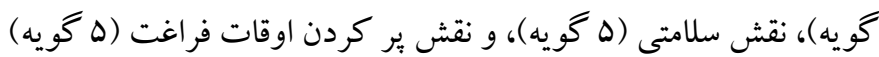

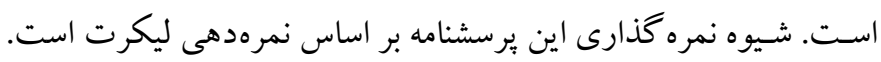

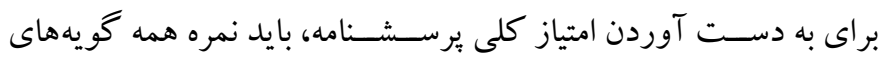

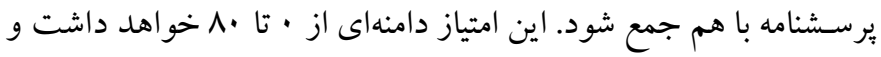

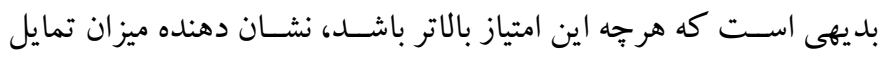

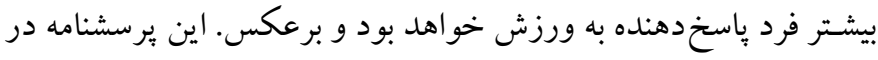

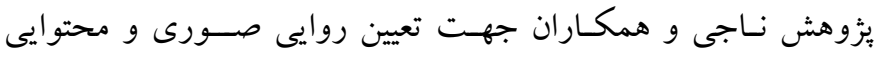

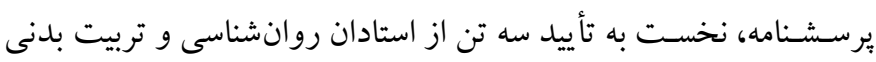

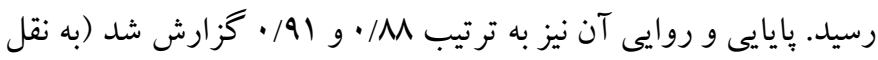
. ( Y

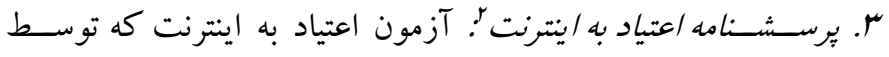

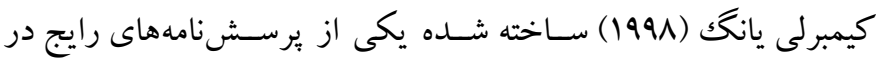

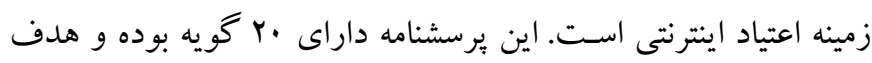

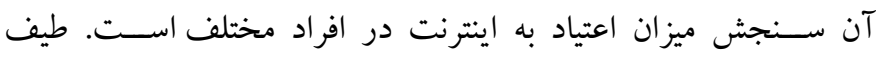

جدول 1: شاخص هاى توصيفى و ماتريس همبستكى متغيرهاى ثزوهش

\begin{tabular}{|c|c|c|c|c|c|c|c|c|c|}
\hline 7 & 0 & $\varepsilon$ & $r$ & $r$ & 1 & انحر اف استاندارد & ميانكين & متغير & شماره \\
\hline & & & & & 1 & $\Delta / \wedge q$ & VN/IF & تمايل به ورزش & 1 \\
\hline & & & & 1 &.$/ \cdot Y \Lambda$ & $1 . / 1 r$ & $F F / 9 \mathrm{~V}$ & اعتياد به فضاى مجازى & r \\
\hline & & & 1 & 米./rA & $*-\cdot / 1$ &.$/ 919$ & $r / \mu_{\Lambda}$ & ميزان درآمد & $r$ \\
\hline & & 1 & $* / 9 Y 9$ & $* \circ / 11$ &.$/ \cdot 9$ &.$/ 9$ & T/FF & طبقه اجتماعى & f \\
\hline & 1 &.$/ \cdot 9$ &.$/ .4$ &.$/ \cdot 10$ & $* / 119$ &.$/ 90$ & r/r & ميزان تحصيلات & $\Delta$ \\
\hline 1 & $\cdot / \cdot r$. &.$/ .14$ & . &.$/ 1$ & .1949 & $1 / 4 \wedge$ & $r / 90$ & وضعيت مسكن & 4 \\
\hline
\end{tabular}


كردند. متغيرهاى طبقه اجتماعى، وضعيت مسكن و اعتياد به فضاى مجازى جون تأثير معنادارى بر تمايل به ورزش نداشتند از معادله حذف شدند. در جدول r نتايج تحليل ركرسيون گزارش شدهاند.
براى بيشبينى تمايل به ورزش از روى متغيرهاى اعتياد به فضاى مجازى و وضعيت اجتماعى - اقتصادى از رگرسيون جند گُانه به صورت كام به گام استفاده شد. در گام اول، متغير ميزان تحصيلات و در كام دوم ميز ان در آمد وارد معادله شده و معنادارى خود رادر طى اين دو كام حفظ

جدول r: خلاصه مدل ركر سيون، تحليلواريانس و مشخصه هاى آمارى ركرسيون تمايل به ورزش بر متغيرهاى اعتياد به فضاى مجازى و وضعيت اجتماعى-اقتصادى

\begin{tabular}{|c|c|c|c|c|c|c|c|c|c|c|}
\hline S.E & $\Delta \mathbf{R}^{2}$ & $\mathbf{R}^{2}$ & $\mathbf{R}$ & $\mathbf{P}$ & $\mathbf{F}$ & ميانكين مجذورات & df & مجموع مجذورات & مدل & كام \\
\hline \multirow{2}{*}{ ه/^G } & \multirow{2}{*}{.$/ \cdot 1 r$} & \multirow{2}{*}{.$/ \cdot 14$} & \multirow{2}{*}{.$/ 119$} & \multirow{2}{*}{$* \cdot / \cdot r \Lambda$} & \multirow{2}{*}{ F/rrr } & IFN/AF & 1 & IFA/AF & ركرسيون & \multirow{2}{*}{1} \\
\hline & & & & & & $M F / F F$ & MIN & $1.9 \Delta Y / \Delta F$ & باقيمانده & \\
\hline \multirow{2}{*}{$\Delta / \wedge r$} & \multirow{2}{*}{$\cdot / r \Delta$} & \multirow{2}{*}{.$/ \mathrm{TV}$} & \multirow{2}{*}{.$/ 190$} & \multirow{2}{*}{.$/ .14$} & \multirow{2}{*}{$F / F \Delta$} & $101 / 9$. & r & $r \cdot r / r$ & ركرسيون & \multirow{2}{*}{ r } \\
\hline & & & & & & $\mathrm{HF} / .9$ & riv & 1. V91/11 & باقيمانده & \\
\hline
\end{tabular}

سطح ه • • معنادار است كه نشان مى دهد متغيرهاى فوق بر تمايل كود كان به ورزش، اثر معنادارى دارد. همجنين در جدول سنيز ضرايب ركرسيون

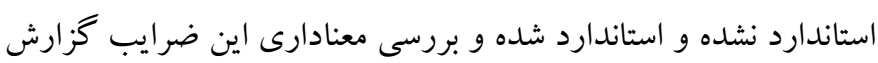

شدهاند.
بر اساس نتايج مندرج در جدول Y مىتوان نتيجه كرفت كه در تبين تمايل به ورزش در كود كان از روى تحصيلات و در آمد والدين، مجموع متغيرهاى بيشبين RV از از واريانس متغير ملاكك را بيشبينى مى كنند. همجينين ميزان F مشاهده شده براى كل متغيرهاى يثوهش در

جدول با: ضرايب ركر سيون استاندارد شده و بررسى معنادارى اين ضرايب

\begin{tabular}{|c|c|c|c|c|c|}
\hline معنا دارى & $\mathbf{T}$ & $\beta$ & خطاى استاندارد b & B & متغيرها \\
\hline 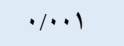 & $9 \mathrm{~V} / 9 \Lambda$ & & $1 / 10$ & $V N / Y F$ & عرض از مبداء \\
\hline$\% \mathrm{YV}$ & $r / r)$ & ./Mr & $\cdot / \mu q$ & $\cdot / \sqrt{ } 9$ & تحصيل \\
\hline.$/ \mu_{F}$ & $-r / I r$ &.$- / 11 \wedge$ & 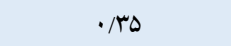 & $-\cdot / v \Delta$ & در آمد \\
\hline
\end{tabular}

ابتدايى شهرسـتان رشـت يرداخته شد. تجزيه و تحليل يافته هاى يزٔوهش حـاضــر نشــان داد بين تمـايـل بـهـ ورزش دانش آموزان مقطع ابتدايى با وضسعيت اجتماعى -اقتصـادى والدين (سـطح در آمد و تحصيلات)، رابطه معنادارى وجود دارد. يافته اين يزوهش با نتيجه بثزوهش سـبرا، مندونكا، تاميس، بيترز و مايا (N)، اســلامى، محمودى، كبيرى و رضــوى (II) و كولز، مارتلار، سـاماى و آندريس (9) همخوانى دارد. سبرا و همكارانش به بررسـى ارتباط بين مشـاركت ورزشـى، عو امل جمعيتشــاختى و اجتماعى فرهنگى در كود كان و نوجوانان يرتغالى يرداختند. يافته هاى آنها نيز نشان داد كه نوجوانان با موقعيت اجتماعى و فرهنكى بالا، بيشتر در فعاليتهاى ورزشى مشـار كت داشـتند. همجينين، اسلامى و همكاران در يثوهش خود به بررسى نقش وضعيت اجتماعى - اقتصادى در انخيزه مشـار كت شـهروندان به ورزش هاى همخانى - تفريحى يرداختند. نتايج
بـا توجـه بـهـ جـدول ب اثر تحصــيـات والدين بر كرايش به ورزش

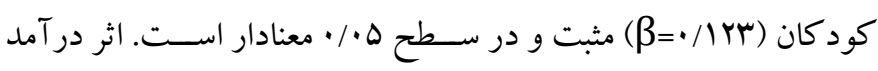

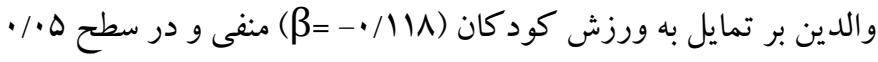
معنادار اسـت. مثبت بودن اثر متغير سـطح تحصـيلات والدين بر كرايش كود كان به ورزش نشـان دهنده آن اسـت كه هر جقدر سـطح تحصـيلى والدين بالاتر باشد، ميزان كرايش به ورزش بيشتر است؛ اما منفى بودن اثر در آمـد نشــانكر آن اســت كـه هر جقتـدر ميزان در آمـد و الدين بيشــتر باشد، گرايش كود كانشان به ورزش، كمتر ديده شده است.

\section{بحث و نتيجه تيرى}

در اين يثزوهش به بررسـى رابطه و نقش وضـعيت اجتماعى - اقتصـادى والـدين و ميزان اعتيـاد بـه اينترنت با تمايل به ورزش دانش آموزان مقطع 


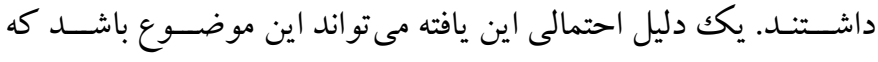

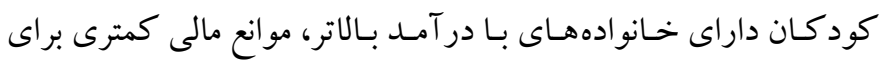

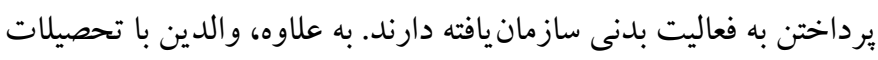

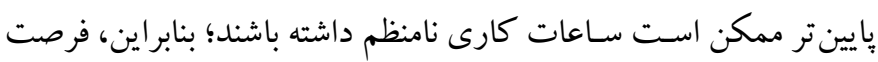

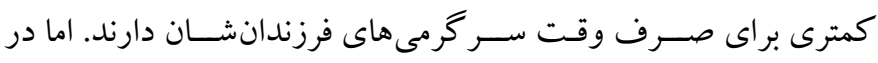
مجموع، نتـايج آنها هيج تفـاوت معنـادارى در فعـاليـت بــنى كلى كلى ميان كود كان با سـطوح متفاوت وضسعيت اجتماعى اقتصـادى نشـان نداد. در

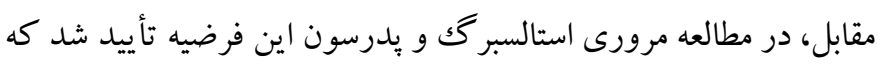
بين وضـعيـت اجتماعى اقتصـادى و فعاليت بدنى ارتباط وجود دارد و

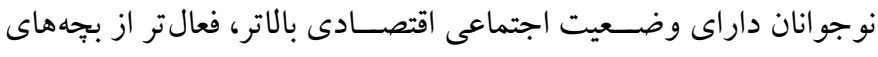
دار اي وضعيت اجتماعى اقتصادى يايين هستند؛ اما بF درصد از مطالعات

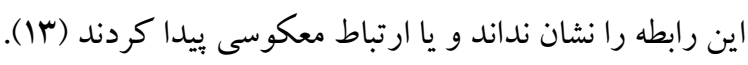

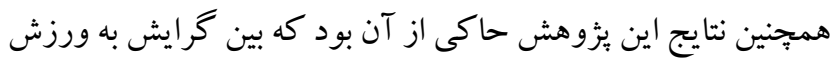

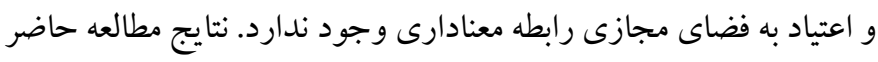

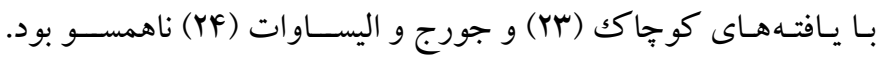

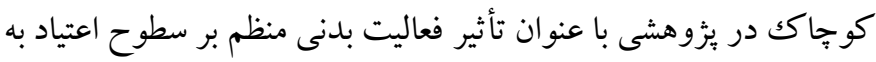

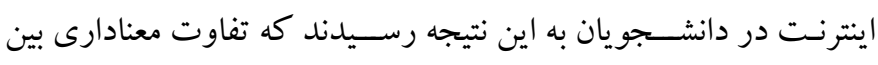
ورزش منظم و اعتيـاد به اينترنت وجود دارد. همجنين، دوره اسـتفاده از

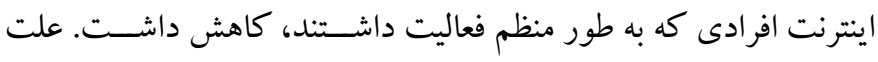

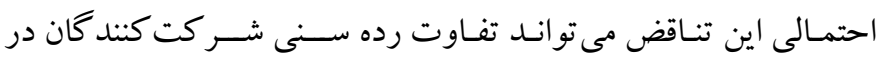

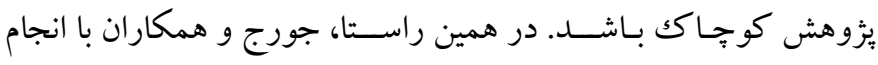

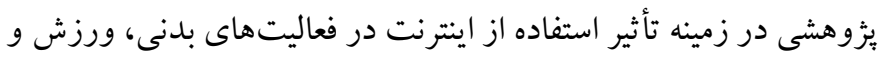

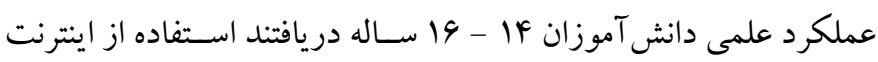

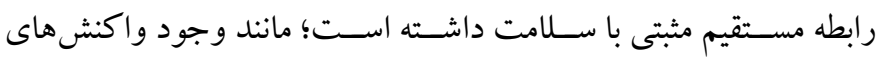

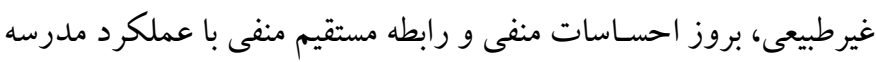
دانش آموزان نوجوان.

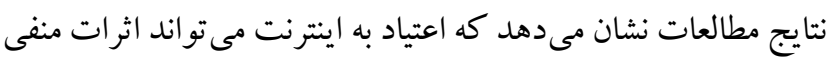

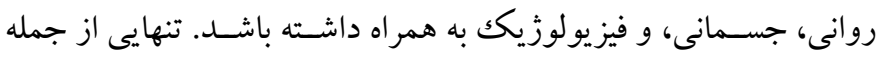
دلايل اعتياد به فضاى مجازى است. به علاوه، افرادى كه زمان طولانى ترى مئى

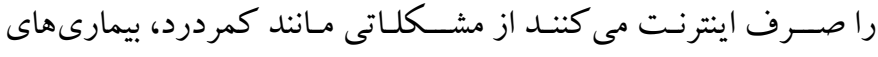
قلبىعروقى و جـاقى رنج مىبرنــد و يـك رابطهه خطى ميـان اســفــاده

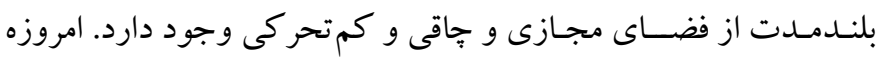

نشـان داد كه بين وضسعيت اقتصـادى اجتماعى با انكيزه مشـار كت رابطه مثبـت و معنادارى وجود دارد و از بين مؤلفه هاى اقتصــادى اجتماعى به ونه

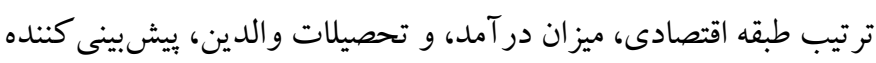
قوى ترى براى انگيزه مشاركت ورزشى در بين شهروندان شهر مشهد بو دود.

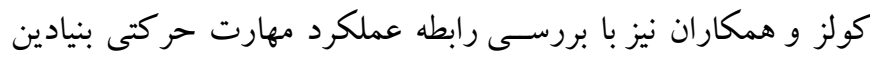

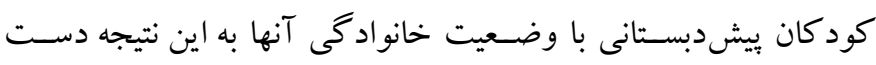

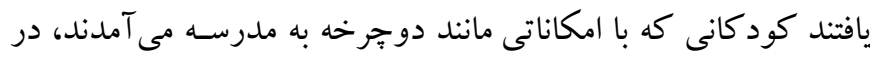
فعاليت هاى ورزشى مدرسه فعال و بيشرفته تر بودند.

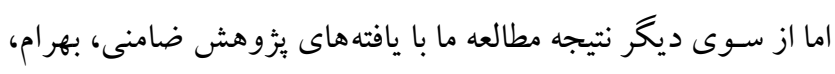

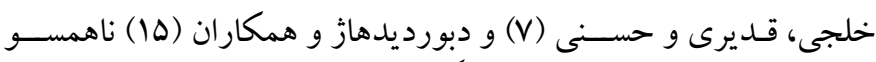

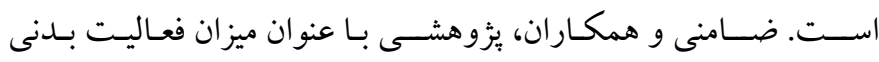

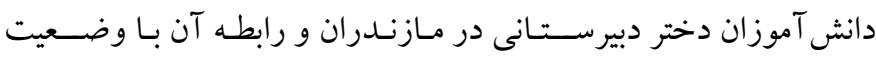

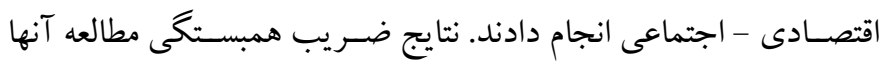
نشـان داد كه بين وضـعيت اقتصادى اجتماعى و سطح فعاليت بدنى رابطه

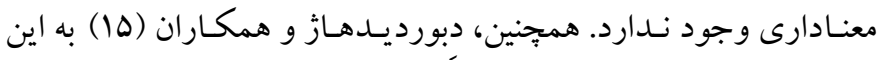
نتيجه رسيدند كه در مجموع ميان وضعيت اقتصادى اجتماعى و فعاليت

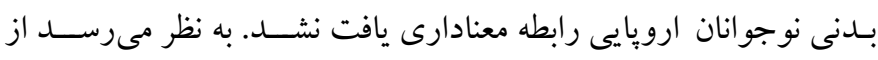

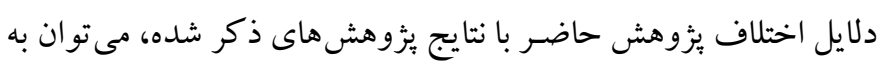

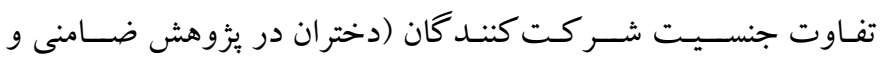

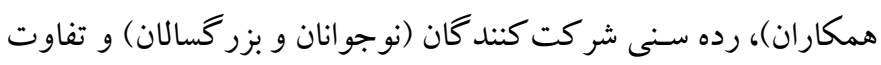
فرهنكى و اجتماعى (در يزّوهش دبورديدهاز ) اشاره كرد.

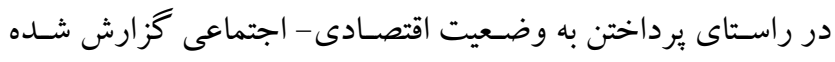

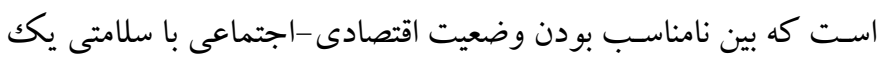
رابطه عليتى دوسـويه وجود دارد؛ به طورى كه برخوردارى از وضسعيت

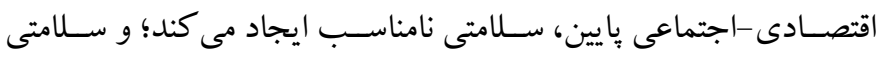
نامناسب نيز به نوبه خود باعث تثبيت و يايدارى فقر مى شود ( • (1). نتايج

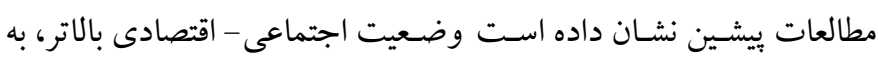
بهبود وضسعيت سـلامتى منجر مى شـود (4-11) و والدينِ داراى وضسعيت

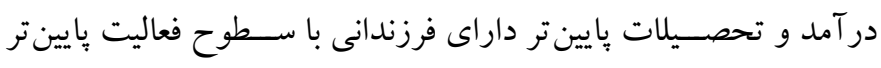

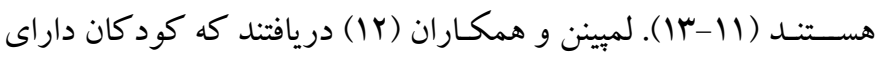
والدين با تحصيلات و در آمد بيايين، سطح بايين ترى از فعاليت بدنى تحت

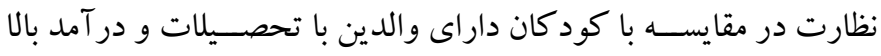


منظم اسـت. بنابر اين بيشــهاد مى شـود اجر ايى ورزش و فعاليت بدنى از

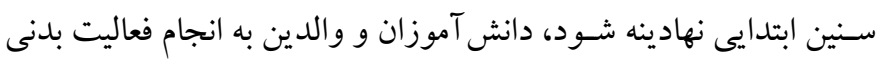

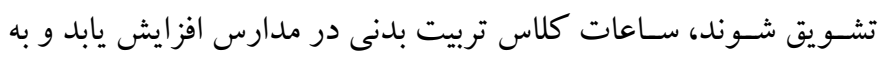
غنىسازى برنامههاى ورزشى و كلاس هاى تربيت بدنى در مدارس توجه

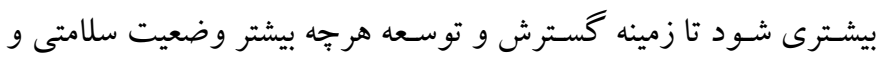
نشاط جامعه فر اهم شود.

ملاحظات اخلاقى ييروى از اصسول اخلاق يخوهش: اين مقاله بركرفته از بايان نامه كارشـناسى ارشد رشـه مديريت ورزشى نو يسنده نخست استخراج شده است كه در و احد رشت دانشخاه

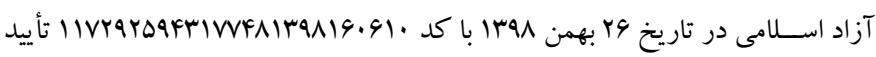

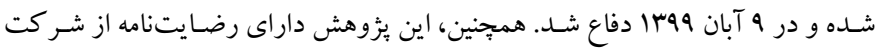
كنند كان با رعايت حفظ حريم شخصى و رازدارى است. حامى مالى: اين مطالعه بدون حامى مالى و در قالب بايان نامه كارشـناسى ارشد انجام ردام شده است. نقش هر يكك از نويسـند كان: نويسنده نخست به عنوان مجرى يُوهش حاضر است و نويسنده دوم به عنوان استاد راهنماى بايان نامه در اين مقاله نقش داشتند. تضاد منافع: اين يثزوهش براى نويسند كان هيج گُونه تضاد منافعى نداشته است.

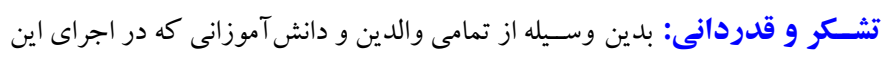
پايانامه به ما كمكك كردند، تشكر و قدردانى مى شود.
اهميت زندگى فعال براى سـلامت فردى و اجتماعى ملموستر شده است

در مجموع، يافته هاى يثوهش حاضر نشان داد بين متغيرهاى كرايش به ورزش و ميز ان اعتياد به فضـاى مجازى با سـطوح وضسعيت اجتماعى اقتصــادى (ميزان در آمـد، طبقـهـ اجتمـاعى و تحصــلات والدين) رابطه معنادارى وجود دارد. طبق يافته هاى به دست آمده مىتوان نتيجه گرفت كـه وضــعيت اجتماعى - اقتصــادى والدين مى تواند بهطور مســتقيم و غيرمسـتقيم بر ميزان تمـايـل كود كان به اجراى ورزش و فعاليت بدنى و اعتياد به فضاى مجازى تاثير داشته باشد.

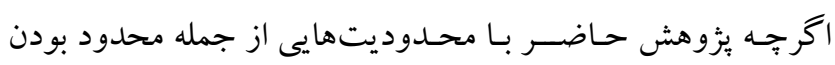
جامعه يُزوهش به دانش آموزان مقطع ابتدايى، بررسـى نكردن ورزشـكار بودن يـا نبودن والـدين و دانش آموزان بـه عنوان متغير ميانجى مواجه بود

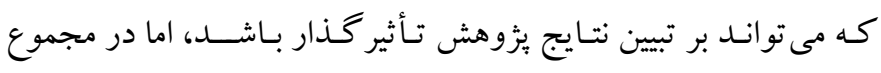
مى توان بر اسـاس يافته هاى به دسـت آمده ادعا كرد كه كود كان داراى والدين با در آمد و سطح تحصيلات بالاتر، داراى تمايل به ورزش بيشتر و سطح فعاليت بدنى بالاتر هستند. از آن جايى كه سطح يايين فعاليت بدنى مهم ترين عامل خطرزا براى سـلامت جامعه اسـت، مؤثرترين روش مورد نياز، بهبود سـلامت عمومى و تشـويق بيشتر جامعه به اجر اى فعاليت بدنى 


\section{References}

1. Zeinali E, Amir Moghaddam, Ghasemian Moghadam M. The Relationship between Body Composition Features and Sustained Attention in Children. J Child Ment Health. 2018; 4 (4):130-139. [Persian]. [Link]

2. Mohammadi L, Hejazi Deanan P, Shamsipour Dehkordi P. The Role of the Developmental Environment (Home, Kindergarten, and Nursery) on the Intelligence Quotient and Social Skills of Children. J Child Ment Health. 2019; 6 (3):126-137 [Persian]. http://dx.doi.org/10.29252/jcmh.6.3.12 [Link]

3. Akbari, Askarian F, Jafari S, Akbari Nasim. Impact of Socio-Economic factors on sports participation in Maragheh Households. Sport Management and Development, 2017; 6(1): 105-116. [Persian]. [Link]

4. Keshavarz, L., Ansari, S. Regression analysis of the attitude of managers, teachers and students about teachers of sports. Applied Research in Sport Management, 2015; 4(1): 35-47. [Persian]. [Link]

5. Pahlavan, M., Barzigar, F. The Effective Social Factors Influencing on the Attitude of Leisure Time among Female Students in Amol. Sociological Studies of Youth, 2011; 2(3): 53-66. [Persian]. [Link]

6. Johansson LM, Lingfors H, Golsäter M, Kristenson M, Fransson EI. Can physical activity compensate for low socioeconomic status with regard to poor self-rated health and low quality-of-life? Health and quality of life outcomes. 2019; 17(1):33. https://doi.org/10.1186 / s12955-019-1102-4 [Link]

7. Zameni L, Bahram A, Khalaji H, Ghadiri F, Hasani G. The Level of Physical Activity of Female Junior High School Students in Mazandaran, Iran, in 2017 and Its Relationship with Socioeconomic Status. J Chem Health Risks. 2018; 7 (1):11-17. [Persian]. [Link]

8. Seabra AF, Mendonça DM, Thomis MA, Peters TJ, Maia JA. Associations between sport participation, demographic and socio-cultural factors in Portuguese children and adolescents. Eur J Public Health 2008; 18(1):25-30. https://doi.org/10.1093/eurpub/ckm049 [Link]

9. Cools W, De Martelaer K, Samaey C, Andries C. Fundamental movement skill performance of preschool children in relation to family context. J Sports Sci. 2011; 29(7):649-60. https://doi.org/ $10.1080 / 02640414.2010 .551540$ [Link]

10. Dollman J, Lewis NR. The impact of socioeconomic position on sport participation among South Australian youth. J Sci Med Sport. 2010; 13(3):31822.https://doi.org/10.1016/j.jsams.2009.04.007 [Link]
11. Eslami, A., Mahmoudi, A., Khabiri, M., Najafiyan Razavi, S. The role of socioeconomic conditions in the citizens' motivation for participating in public sports. Applied Research in Sport Management, 2014; 2(3): 89-104. [Persian]. [Link]

12. Lampinen EK, Eloranta AM, Haapala EA, Lindi V, Väistö J, Lintu N, et al. Physical activity, sedentary behaviour, and socioeconomic status among Finnish girls and boys aged 6-8 years. Eur J Sport Sci. 2017; 17(4):462-72.https://doi.org/10.1080/17461391.2017 .1294619 [Link]

13. Stalsberg R, Pedersen AV. Effects of socioeconomic status on the physical activity in adolescents: a systematic review of the evidence. Scand J Med Sci Sports. 2010; 20(3):368-83. https://doi.org/10.1111 /j.1600-0838.2009.01047.x [Link]

14. Piko BF, Keresztes N. Sociodemographic and socioeconomic variations in leisure time physical activity in a sample of Hungarian youth. Int J Public Health. 2008; 53(6):306-10. https://doi.org/10.1007 /s00038-008-7119-9 [Link]

15. De Bourdeaudhuij I, Simon C, De Meester F, Van Lenthe F, Spittaels H, Lien N, et al. Are physical activity interventions equally effective in adolescents of low and high socio-economic status (SES): results from the European Teenage project? Health Educ Res. 2011; 26(1):119-30. https://doi.org/10.1093/her/ cyq0 80 [Link]

16. Amani kolarijani, A. Cyberspace and Explore Preventive Policies to Control Newly Encouraged Social Violence. Crime Prevention Approach, 2017; 0(1): 89-106. [Persian]. [Link]

17. Ching SM, Hamidin A, Vasudevan R, Sazlyna MS, Wan Aliaa WS, Foo YL, et al. Prevalence and factors associated with internet addiction among medical students-A cross-sectional study in Malaysia. Med J Malaysia. 2017; 72(1):7-11. [Link]

18. Doosti Irani A, Bagheri Amiri F, Khajehkazemi R, Mostafavi E. Prevalence of internet addiction among students and graduates of epidemiology, clinical sciences, and basic sciences in Iran: A cross-sectional study. Iranian Journal of Epidemiology. 2017; 13(1):14-21. [Persian]. [Link]

19. Tajik Esmaeili, Ph.D. S, Ardekanian R. Examining the Impact of Internet Addiction on Students' Social Skills in Smart and Regular Schools. Quarterly Journal of Family and Research. 2015; 12 (2):7-26. [Persian]. [Link]

20 Ha JH, Kim SY, Bae SC, Bae S, Kim H, Sim M, et al. Depression and Internet addiction in adolescents. 
Psychopathology. 2007; 40(6):424-30. https://doi. O rg/10.1159/000107426 [Link]

21. Rashidiyan S, Rashidi N, Ghanbari N. Prediction of Internet Addiction in Students based on Social Support and Academic Expectations Stress. J Child Ment Health. 2017; 4 (3):176-186. [Persian]. [Link]

22. Gunuc S, Dogan A. The relationships between Turkish adolescents' Internet addiction, their perceived social support and family activities. Comput Human Behav. 2013; 29(6):2197-207. https://doi.org/ 10.1016/ j.chb.2013.04.011 [Link]

23. Koçak ÇV. How does regular exercise affect internet addiction level in university students? Physical education of students. 2019; 23(4):186-90. [Link]

24. George L, Elisavet P. The impact of the internet use in physical activity, exercise and academic performance of school students aged 14-16 years old. International Journal of New Technology and Research. 2017; 3:12-6. [Link]

25. Malak MZ, Khalifeh AH, Shuhaiber AH. Prevalence of Internet Addiction and associated risk factors in
Jordanian school students. Comput Human Behav. 2017; 70:556-63. https://doi.org/10.1016/j.chb.2017. 01.011 [Link]

26. Ghodratnama, A., Heidarinejad, S., davoodi, I. The Relationship between Socio - Economic Status and the Rate of Physical Activity in Shahid Chamran University Students of Ahwaz. Journal of Sport Management, 2013; 5(16): 5-20. [Persian]. [Link]

27. Tabrizi Yeganeh M, Korooki A, Sanei HR. The relationship between the desire to exercise and social vitality in physical education students of Hormozgan province. The first national conference on the achievements of sports science and health. 2017. [Link]

28. Young KS. Caught in the net: How to recognize the signs of internet addiction--and a winning strategy for recovery. John Wiley \& Sons; 1998.

29. Nastiezaie N. The Relationship between general health and internet addiction, Zahedan J Res Med Sci. 2009; 11(1): 57-63. [Link] 